\title{
THE PECKHAM EXPERIMENT
}

\author{
by
}

\author{
KENNETH BARLOW*
}

[Editorial Note: The Pioneer Health Centre at Peckham (often called the Peckham Health Centre) has recently attracted a good deal of historical attention, including an article in this journal by Jane Lewis and Barbara Brookes (Med. Hist., 1983, 27: 151-161). The author of the present article, Dr Kenneth Barlow, has long been associated with the Pioneer Health Centre Ltd, presently serving as its vice-chairman. He believes that the philosophy which underpinned the activities of George Scott Williamson, Innes Pearse, and their associates has been insufficiently appreciated by historians and health professionals alike. Accordingly, we have been pleased to allow him to expound that philosophy "from the inside", and hope that our readers will find it a convincing example of the kind of thinking that led to the Peckham experiment.]

In October 1984, the Journal of the Royal Society of Medicine, commenting on a discussion paper by Dr Court, ${ }^{1}$ reported that the Royal College of General Practitioners and the General Medical Services Committee of the British Medical Association are producing a record card for use in general practitioner and other clinics which undertake "developmental surveillance".

The function of [the proposed] clinics is threefold. Firstly, there is the examination of all babies at appropriate intervals to see that they are growing normally ... and that such disabilities or potential disabilities as warrant intervention can be identified so that remedial action can be taken .... The most important tests are those directed at identifying congenital dislocation of the hips, squint, hearing loss and, in boys, maldescent or nondescent of the testes. Other tests are directed at identifying any defects in the four major functions; gross and fine motor, coordination and language development. ${ }^{1 a}$

This is a classical medical approach. It proposes the surveillance of the person whilst looking for disability. It pays little heed to that person's "environment".

In terms of the "maximum potential" of childhood, the relevant "environment" comprises everything which surrounds or environs the child. When we look at the child's surroundings, particularly in its earliest years, what we chiefly see are other people; particularly the parents, the siblings, and the place on which they are all based. Since the child depends on nurture, the pattern, not only of its intimate

*Kenneth Barlow, FRCR, DMR, MRCS, LRCP, Vice-Chairman, Pioneer Health Centre Ltd., Shouler's End, Thornborough, Buckingham MK18 2DH.

${ }^{1}$ S.D.M. Court, 'Meaning and method in child health surveillance: discussion paper', J. R. Soc. Med., 1984, 77: 863-865.

'a Stuart Carne, 'Place of developmental surveillance in general practice', ibid., 819-820, see p. 819. 


\section{The Peckham experiment}

surroundings, but of what in turn surrounds this larger biological unit may, somewhat unconventionally, be seen as the essence of the child's "environment".

Nurture implies that the child depends upon its environment for its development. "Development", like "environment", repays examination. As John Hunter said in the eighteenth century, living systems have a principle of action in every part. This is the difference between the living system and the machine-which is powered from without. When there is health, the principles of action, present in every part, are seen to work together. They are able to do so in virtue of the synthesis which all the parts of the living system, and the system itself, effect with their surroundings or environment. The person whom the child makes, is made out of the environment by its intake both of food and of experience, and this by its inherent abilities; the environment, meanwhile, is made out of other living systems. These constructional, metabolic, achievements have constant features but they also show great individual variation resulting in the distinctiveness not only of the fingerprint and the voice pattern but of biochemistry and behaviour.

Half a century ago, in 1935 and the years that followed, George Scott Williamson began to use medical tools and other facilities not merely for the identification of disability, but in order to study development in the sense just described and the latent power of health implicit in such development. He located his endeavour in a leisure centre for whose construction he was responsible; this was available only to local families. In order that he might be aware of the "environment" of the growing child, he made it a condition of membership that the child's "environment" should come within his field of observation. This he achieved by rules which laid it down that membership should be restricted to whole families and that all members of all families should periodically attend for medical overhaul. He sought to pursue his enquiries through two channels. Through one channel the condition of individuals at every stage of development would be revealed by medical examination and by consultation with those concerned. Through the second channel, observation of the leisure activities of families (the behaviour of individuals and families as they went about their leisure affairs within their community) would be made possible.

As we look back from 1985, we are able to distinguish two points of view. The conventional view is that the service of health-and health service-is best arrived at by the cure and care of disability. The other view, on which the Peckham experiment was based, is that the service of health requires detailed understanding of the way in which biological unities (biological molecules, cells, tissues, organs, systems, individuals, families and communities) are disposed to integrate. Since in every instance the relevant principle of action is inherent in the part of the living system concerned, the service of health needs to understand the way in which living systems develop and function.

The Pioneer Health Centre, functioning between 1935 and the onset of the second world war, gave information about the lives and actions of a local community of families all living in one defined area. Those who observed these occurrences saw that, at first, people's behaviour was in the main decided by their previous experience. They behaved as they had been accustomed to do in their urban environment before the Centre was built. The objective of the Centre was to modify 


\section{K. Barlow}

that pre-existing environment. Previously, members were accustomed to being directed. They expected to be told what they were and what they were not allowed to do. They expected the staff to organize their leisure affairs and to instruct. But that was not what the experiment was about. The experiment sought to identify the principles of action and, equally, the principles of development and integration which were inherent in people-as distinct from being instilled or grafted into them. These principles of action took time to assert themselves but eventually they did so; members began to integrate and to realize untapped potential in themselves.

This was a "plan of developmental surveillance" of a kind very different from that now proposed by Dr Court. Not only was the growing child brought within its scope, so also was the parenthood which initiated that development and provided its relevant environment. In this early initiative, not only was surveillance of the development of the growing child secured; there was also an overview of the environment into which the child was begotten. Scott Williamson's view was that both the growing person and the growing person's environment put themselves together in mutual interdependence. He spoke of their mutual synthesis.

Almost a decade before the definitive Pioneer Health Centre was opened in St Mary's Road, Scott Williamson and Innes Pearse had conducted a preliminary enquiry amongst about 100 families, in a small house in the same neighbourhood. ${ }^{2}$ This survey had resulted from concern about perinatal morbidity and mortality as witnessed in an antenatal clinic in the east end of London. Thus, the path which had been trodden tended to lead towards the point of renewal-the point where one generation follows another. From this path one looked out at the development which had been achieved in an inner city location.

The quality of this development was recorded as the first 500 families joined the Centre after 1935 and were examined in the first year. This indicated the starting-point from which the potentials of development were to be studied. The evidence from these examinations indicated that the parental environment into which the children of the Centre were to be introduced was, from a medical standpoint, not very good. These first 500 families comprised 1,666 individuals. Nine out of ten of them were discovered to have some diagnosable medical condition, some of which were serious. Some of those concerned complained of their condition; others did not. ${ }^{3}$

In the ordinary way, folk beget babies either by chance or by intent. The babies grow into the situation into which they are precipitated as, and if, they can. Fertility secures that if one baby cannot achieve such growth another can be provided to try in its turn. The primary aim of the Peckham experiment may be said to have been to monitor these occurrences within a community and thereby to come to understand how ability could be developed to advantage; and, where, (and as possible) disability, along with disorder and disease could be avoided. It could be said to be a biological principle that as a living system becomes aware of its surroundings or environment, that system creatively adapts its abilities to the advantage of its living. It is, of course, not possible to make a newborn baby able to assess the quality of its surroundings or

'I. H. Pearse and G. Scott Williamson, The case for action, London, Faber, 1931.

${ }^{3}$ G. Scott Williamson and I. H. Pearse, Biologists in search of material, London, Faber, 1939, pp. 53-54. 


\section{The Peckham experiment}

environment; but it is possible to make the parenthood, which constitutes and provides the immediate surround of its babe, aware of the dependence of the babe upon the quality of this parental surround.

Individual health is a quality which is created; it is not a commodity which we acquire from a doctor's surgery, from a hospital, or from a chemist's shop. In its beginnings, it occurs as the baby grows into the situation in which it is nurtured, normally by its parents. All of this is so obvious that to state it appears trite-until prestigious "plans for developmental surveillance", concentrate on disabilities. The baby depends on its surroundings (its parenthood) for its nurture. It develops abilities which allow it to make use of elements in its surroundings - the air it breathes, the breast milk it imbibes, and the "experience" which its "nursery", however constituted, provides. Its ability to make use of aspects of its environment expands with that experience. What is relevant to it in its development, widens. New abilities lead to new uses and as they do so there is need to "choose" how to behave and therefore what to use. Of course, what can be used is affected by what the environment makes available. But parents and communities seek to make the environment fit for the rising generation.

In the case of the baby in its nursery, all this is seen in miniature. However, it is underpinned by basic biological principles; those apply throughout the lifespan. The person (as indeed does the family) builds itself by "intake" from its surroundings. Always what is used reinforces the ability to use. What is chosen for use affects the quality of the personality, or the family, which, whether consciously or by custom or instinctively, selects what it employs. Here, both food and experience are involved. It is on these that the metabolism of the personality is based. What is to be seen in miniature in the nursery is recognisable "as large as life", not only in our progress to maturity, but in our living as mature adults.

It was from some such background of ideas that the Peckham experiment set out in 1935 to study this "intake" within a community and this by the two methods which it employed simultaneously (medical overhaul and observation of leisure). It has been said that the individual's intake from his or her environment consists in the main of food and experience. Here "experience" requires to be defined. The dictionary meaning of the word is "the action of putting to the test". It is features in the environment which are "put to the test". What the Peckham experiment studied was the way in which individuals and families went about their affairs "putting to the test" the facilities which the Centre provided. The underlying question was how this reacted on their bodies and their relationships with one another and how this contributed to what is known as "positive health".

The notion of "positive health" tends to carry us beyond the scope of medicine. A highly distinguished professor of Community Medicine at Birmingham University, Thomas McKeown, commented:

It is even more difficult to arrive at a decision about positive health. Subjectively we are all aware that feeling well is something more than not feeling ill and we should like our doctors to regard both as desirable objectives. But knowledge of the biological basis of positive health is still primitive and the parallel measures which can be taken to promote it are so far in the fields of interest of the clergyman and the games master rather than the doctor.4

`Thomas McKeown, Medicine in modern society, London, Allen \& Unwin, 1965. 


\section{K. Barlow}

What the Peckham experiment studied was precisely the biological basis for positive health. It studied the environment within which its member families replaced one generation by another. Conventional organization in our society deals with varying problems-each out of context with others. Each is dealt with by means of a separate, commonly isolated, agency. Each such agency addresses itself to something likely to be seriously wrong. The Peckham experiment provided means by which matters commonly addressed from this standpoint could be seen as they operated together in the day-to-day life of a local community. The endeavour was to understand how they might work together to advantage. Such matters as medical assessment of fitness for childbirth, fitting conduct of pregnancy and delivery, and the postnatal scene in which the newcomer establishes itself in a new world, were all seen in relation to one another. The same integration of perspective was secured in respect of successive phases of development. Positive health, if and when it occurs, is a product, on the one hand, of the ability of biological unities to set themselves up satisfactorily within their environment; on the other hand, it is a product of the fitness of that environment for such a setting up. As development proceeds potential is shed. Favourable circumstances are more efficacious in early life than in age. To the newly conceived child, the environment into which it grows is of major consequence. Fitness to conceive and fitness in pregnancy promise good beginnings. At Peckham, a couple who were about to marry could seek a premarital consultation to assess their biological state. When they decided that they wished to conceive a child they could get a preconceptual consultation-something which a generation later has become the concern of organisations such as Foresight. In ways of this kind, as well as by observation of leisure activity the quality of the intimate environment into which the new individual grew was constantly assessed. The surroundings of the growing child through the successive phases through which it passes-infancy, toddler, pre-school child, and so on-determine the quality of its nurture and of its development. To a large extent, the significance of these surroundings derives from the personal relationships within the family. These are in no small measure affected by what the surroundings allow members of the family to do in their leisure and, indeed, by what they choose to do. Anyone who doubts the significance of such personal relationships should reflect on the findings and troubles of psychiatrists.

It will be clear that successional studies of individual development take time. Anyone who addresses him or herself to such studies must learn as he or she goes along. After four and a half years, the Peckham experiment was interrupted by war. Part of this interval had necessarily been spent in taking the temperature of the water and in devising procedures within which the principles of human development could be observed. When the war interrupted the experiment, it was quite remarkable how much had been learnt by the Peckham observers about the biological interplay between a local urban population of families and its local urban environment.

During the war-in 1943-their report was published. ${ }^{5}$ It sold 50,000 copies and took departments of government and of propaganda by storm. I should perhaps explain that the war had, of necessity, closed down the Pioneer Health Centre; the

${ }^{5}$ I. H. Pearse and L. Crocker, The Peckham experiment. A study in the living structure of society, London, Allen \& Unwin, 1943. 


\section{The Peckham experiment}

children of London were evacuated. The Peckham staff, deprived of what there was to observe, reported on what they had previously seen. A pamphlet written some years after the closing down of the experiment stated:

In the two years subsequent to the publication of the report 'The Peckham Experiment',
published in 1943, no less than 300 lectures were given by staff at the invitation of Universities,
the armed Forces and professional and lay groups of various kinds. These included two tours.
One to forces in the Middle East and one to all forces in the B.A.O.R. at the request of the
educational department of the War Office. Later a tour of Holland was carried out on behalf of
the Foreign Office. Since the war both doctors have been to the U.S.A. by invitation.

This quotation requires to be taken in conjunction with Thomas McKeown's comment on positive health quoted above. He asserted, as late as 1965 , that knowledge of the biological basis of positive health was still primitive. What the Peckham experiment had done a score of years previously was to report on the dependence of positive health upon the life and, particularly, the human life which surrounds the growth and development of the individual human being. The social surroundings of the individual are seen to lie at the centre of the question of environmental health. The Peckham enquiry into the possibility of expanding hitherto primitive knowledge within the compass of biological, ecological and ethological parameters, engaged, for the moment, the interest of universities, the armed forces, and professional and lay groups-this from the Middle East to the U.S.A.

Between 1942 and 1948, there was national concern about the environment into which the post-war generation, both the rising generation and those already adult, would grow. Not inconsiderable in this concern was the question of health. Looking back from 1984 we can now see that, at that time, there were two approaches. One approach was conventional; it was outlined in the Beveridge report. ${ }^{7}$ It stated that health was to be achieved by a comprehensive medical service for every citizen coupled with a minimum income, necessary for subsistence. The other approach was new and for a moment hit the headlines. This latter approach lay not through the doctor's surgery, the hospital, and the chemist's shop but through an exploration of the still uncharted biological basis of environmental health in the sense now defined. The first approach was accepted and embodied in the Act of 1948; the second approach was, to our cost, rejected.

After the war, in circumstances of great difficulty by reason of scarcities but also of great opportunity, the Pioneer Health Centre reopened and 500 families who had been members before the war rejoined. The experiment lasted another four and a half years. It is obvious that war had damaged and destroyed large parts of our environment. I spent the war as a general practitioner in Coventry where destruction was to be seen on every side. Large areas of our environment had to be repaired and reconstructed. Towards the end of the war and when peace came, there were half a dozen places in Great Britain where there were plans to make use of the lessons learnt at Peckham. However, largely by reason of scarcity, everything was controlled. Only those projects which received governmental approval were facilitated. There was, however, great concern about national health. The question

${ }^{6}$ G. Scott Williamson and I. H. Pearse, The passing of Peckham, London, [the authors], 1951.

${ }^{7}$ Beveridge Committee, Social insurance and allied services, Cmd 6404, London, HMSO, 1942. 


\section{K. Barlow}

was, from what did national health derive? The Minister, Aneurin Bevan, was challenged from several sides because at that time the repute of Peckham was high. Bevan did what ministers do. He took advice. In particular he took the advice of Bradford Hill of the Medical Research Council, the father of statistics, and of Rock Carling, then one of the trustees of the Nuffield Foundation. Both of these gentlemen trod in the footsteps of Beveridge; besides, Bradford Hill needed records, and what records were there of positive health?

Prior to legislation in 1948 the Peckham experiment had asked the government of the day whether its studies of the relation of local families to their local environment did or did not constitute a major and important route to positive health. Governed by its advisers, the Government, with great emphasis, replied that it did not-that the route to health had been indicated by Sir William Beveridge and was pursued by doctors and by social services.

If a generation of man is taken as thirty years, then a full generation has elapsed since the 1948 legislation about health. During that time demand for sickness services has steadily increased. The National Health Service has become the largest employer of labour with over a million people in its service. On the other hand, reports of positive health are far to seek. The sickness which results from the way in which people grow into their world has to be considered against the fact that the making of that world is potentially so largely in their keeping.

The underlying biology should be recalled. Over the aeons, the many forms of life have given rise to a human environment which, given some control of population, offers (potentially) abundance of supply. Man has acquired abilities which, if applied, would allow him to administer and to use this potential abundance to his biological advantage. To this end he would require to understand the local conditions within which individuals, individual families, and local communities develop and integrate according to their biological imperatives. ${ }^{8}$ This is not something which is realized by what are held to be the imperatives of economics. It was, however, the subject matter of study by the Pioneer Health Centre.

The studies of the Pioneer Health Centre have been compared to the practices of contemporary society and assessed in terms of economics and current social ideas. This, for instance, was the basis of recent articles by Lewis and Brookes. ${ }^{9}$ The effect of this comparison is to reinforce the current policies, to lose sight of the problems associated with positive health, and to re-establish current sociological orthodoxy.

Since the war, urban environments have been reconstructed-often in tower blocks. Has this reconstruction taken into account the leisure of families or the development of the children born into those families? Is it not true that during the first five years of a child's life it develops as, and if, it can in circumstances, often isolated, in which its parenthood commonly has little association with its comings and goings. Certainly, it cannot be said that this reconstruction paid the slightest

\footnotetext{
- Roger T. Williams, Biochemical individuality, Chichester, John Wiley, 1956.

'Jane Lewis and Barbara Brookes, 'The Peckham Health Centre, "PEP", and the concept of general practice during the 1930s and 1940s', Med. Hist., 1983, 27: 151-161;idem, 'A reassessment of the work of the Peckham Health Centre, 1926-1951', Millbank Memorial Fund Quart./Health and Society, 1983, 61: 307-350.
} 
attention to the experience gained in the Pioneer Health Centre and discussed in its reports.

In the course of the postwar reconstruction, some five hundred Leisure Centres have been built in Great Britain, many costing many millions of pounds. Has any one of these been used to enquire into the questions which concerned the Peckham experiment? The centres have merely conformed to the pre-existing habits of the society whose demands on the Comprehensive Medical Service exceed what can be met. Nowhere has a centre looked back over its shoulder at the successions of human development. These, however, require to be provided for, facilitated, and indeed understood if the leisure life of families is indeed to result in progress towards health.

Even the other side of the coin has not been examined. The Pioneer Health Centre, by periodic overhaul of a local population, disclosed the extent of diagnosable medical conditions in a sample population-conditions which give rise to the unsatisfied demands presently made upon our comprehensive medical service. Since the National Health Service was initiated in 1948, no survey has been attempted in order to repeat this enquiry and to obtain comparable information. Governments have been advised to avoid such enquiries because they may find themselves unable to cope with what is revealed-something which is said not to be "cost effective".

Living systems offer mankind an environment which is capable of favouring their development provided that they understand the conditions in which their positive health can be approached. That environment is in large measure committed to management by human beings. Is it not desirable to illuminate this overall objective and to return to that which our biology has to teach us concerning how such management can be effected? 